\title{
QUALITY OF LIFE IN PATIENTS WITH RESECTED OESOPHAGEAL CANCER
}

\author{
F. C. E. van Knippenberg, ${ }^{1}$ J. J. Out,${ }^{1}$ H. W. Tilanus, ${ }^{2}$ H. J. Mud,${ }^{3}$ \\ W. C. J. Hop ${ }^{4}$ and F. VERHAGE ${ }^{1}$ \\ ${ }^{1}$ Department of Medical Psychology and Psychotherapy, Erasmus University Rotterdam, P.O. Box \\ 1738, 3000 DR Rotterdam, ${ }^{2}$ Department of Surgery, University Hospital Rotterdam Dijkzigt, \\ ${ }^{3}$ St Clara Hospital, Rotterdam and ${ }^{4}$ Department of Epidemiology and Biostatistics, Erasmus University, \\ Rotterdam, The Netherlands
}

\begin{abstract}
Quality of Life (QL) is hard to assess and seldom measured in patients having carcinomas with an unfavourable prognosis. Oesophageal cancer is one of the malignancies with a low 5-year survival rate. Dysphagia (problems in swallowing food) is considered to be the most important indicator of QL in patients with oesophageal carcinoma. Moreover, the psycho-social aspects and subjective QL in cancer have recently gained importance.

The present study investigated QL in a 132 patients with oesophageal cancer. Eighty-three of them had a surgical operation (removal of part of the oesophagus and part of the stomach, followed by a reconstruction of the digestive tract). Sixty-seven patients filled in questionnaires before and after the operation. Complete sets of data were obtained from 62 patients. Time interval between operation and postoperative assessment varied from 3 to 7 months. Indicators of QL were: Psychological Distress, Physical Symptoms, Global Evaluations, Activity Level, Swallowing Problems and Food Intake. Swallowing Problems showed moderate correlations with the other QL indicators. Physical Symptoms increased, whereas the Activity Level, Psychological Distress, and Swallowing Problems decreased; Global Evaluations remained unaltered.
\end{abstract}

Key words-oesophageal cancer, Quality of Life, physical and psychological distress, global evaluations

\section{INTRODUCTION}

In recent years, the number of studies on the Quality of Life (QL) of patients with malignant disease has increased steadily $[1,2]$. This is partly due to higher survival rates for some cancers, with a consequence that more attention is paid to the quality of this 'longer' life. Treatment, however, does not guarantee cure. It is, therefore, mandatory to weigh the pros and cons of treatment, for instance by balancing the risks or side-effects (and QL) against the chance of a longer life [3].

Researchers in the field of psychosocial consequences of cancer use different definitions for $\mathrm{QL}$ and they seldom agree on how best to measure it $[1,4,5]$. Important indicators of a deteriorated QL are often considered to be evident physical impairment (mutilation or other side-effects of treatment, such as amputations, nausea, vomiting, hair-loss), loss of autonomy, general impairment and the need for physical care. The use of such indicators is based on the physicians' assumption that physical impairment or serious side-effects of treatment are strongly associated with negative well-being, and consequently result in a poor QL. These seemingly objective somatic indicators (i.e. observable consequences, weighed subjectively by physicians) have gradually

* Curative treatment is intended to cure and contrasts with palliative treatment: the intention to relieve symptoms. been replaced by self-assessed evaluations of patients. Large differences appear to exist between individuals when evaluating the objective physical and social consequences of cancer. Within this self-assessed approach, psychological distress, experienced physical symptoms (in contrast to symptoms of great clinical relevance), activity level and-sometimesglobal evaluations, are used as indicators for QL $[1,5]$ in the majority of studies.

Only few QL-studies have been conducted with patients having oesophageal cancer. Oesophageal cancer has a highly unfavourable prognosis $[6,7]$. Five years after the diagnosis, only $5-10 \%$ of all patients with this malignancy, still live [7]. In the sixties and seventies, the 5-year survival rate of patients with a partly removed (resected) oesophagus was about $12 \%$ [7]. This rate increased to $20 \%$ in the eighties [8], due to lower hospital mortality. The 3-year survival rate is now approx. $32 \%$ [6], or perhaps even $50 \%$ [9]. Once oesophageal carcinoma has been diagnosed, the possibilities for curative* treatment have become limited. Surgery is very intrusive and entails a long period of recovery. It consists of a partial resection of the oesophagus, and often also of the upper part of the stomach [6]. The remaining lower part of the stomach is used for reconstruction of the digestive tract. In some cases the stomach is not suitable to bridge the created defect, especially in patients who had a partial stomach resection in the past for a peptic ulcer. In 
these cases the reconstruction is performed with a colon interposition (part of the colon is used to replace the rescetcd parts of the oesophagus and stomach).

In the Netherlands, oesophageal cancer takes an intermediate position in the order of deaths caused by malignancies: a ninth place for men and a fourteenth place for women [10]. It is a form of cancer with a relatively low incidence that is difficult to treat. The male: female ratio is about $2: 1$.

\section{QUALITY OF LIFE AND OESOPHAGEAL CANCER}

A majority of the QL-studies in patients with oesophageal cancer [11-17] reported QL-data of patients recciving palliative treatment [11-15], and problems in the passage of food (dysphagia) were almost always regarded as the most prominent QL-indicator [7, 16, 17]. As one of the authors put it: "Since the original symptom in the majority is dysphagia it is presumed that removal of this should produce a good quality of life ..." [7, p. 386]. Some years earlier, Stoller et al. [18] observed incomplete recordings of swallowing ability in records of patients with palliative treatment for oesophageal cancer: swallowing symptoms had not been recorded in $36.2 \%$ of patients in their study. Effects of treatment on the main symptom are often not registercd and effects on the general well-being of patients are only incidentally investigated. Barbier et al. [13] and Sugimachi et al. [17] used specific indicators (swallowing problems) and psycho-social indicators (e.g. well-being and work resumption)

No improvement in QL was found in some studies $[11,12]$, while improvement was reported in others [13-17]. The results of studies in patients with curative treatment have been positive. More than $70 \%$ of a group of 103 patients in a study by Pralat et al. [16] evaluated their QL positively after treatment. Sugimachi et al. [17] found better food tolerance, less dysphagia, less time needed for food intake and more acceptance of normal food in their patients, one or more years after curative resection. Many of the patients who had been employed before treatment, returned to work afterwards $(90 \%)$ and the performance status was reasonably high in all cases. The overall QL was good in the majority of patients.

At Erasmus University Hospital Rotterdam, a study was initiated on the QL of patients who were surgically treated for oesophageal carcinoma. The purpose of the study was to gain more insight into the (changes in) QL of these patients, by investigating the relations between several $\mathrm{QL}$ indicators and the changes in $\mathrm{QL}$. In our study QL was considered a subjective factor: experienced symptoms, psychological distress, global evaluations, activity level, and problems with swallowing food

\section{PATIENTS AND METHODS}

\section{Patients}

From October 1984 to February 1987, 157 patients with oesophageal cancer were asked to participate in a psychological study. Nine patients refused, and in 12 patients an interview could not be arranged due to medical examinations; 4 patients were physically or mentally unable to participate. QL data were collected from 132 patients before the start of treatment (first assessment). Of these 132 patients, 49 turned out to be inoperable. These patients either underwent chemotherapy, or received radiation therapy, or their symptoms were treated palliatively with an oesophageal tube to improve the passage of food, or the patients received no further treatment. Data from these 49 patients were neglected in the analysis of changes in QL. Eighty-three patients were treated surgically. A second point of assessment was scheduled about 3-4 months postoperatively. The choice of this postoperative interval was based on several considerations. In the first phase of a pilot study we had scheduled a QL-assessment at about three weeks postoperatively. This turned out to be too tiresome for many patients. QL-assessment shortly before discharge appeared to be unpractical: some patients were in a bad condition at discharge (they were transferred to another hospital at a shorter distance from their place of residence, or were discharged to further recover at home.) In other patients, however, recovery was smooth and postoperative hospital stay relatively short. To avoid undue burdens for the patients and the risk of a high drop-out rate, the interval was set at three to four months. Thirty-two of the 49 non-surgical patients had died before we could do a second QL assessment, 3-5 months following the first assessment.

Biographical data are shown in Table 1. Mean age of the non-surgical patients was slightly higher than that of the surgical patients ( $63 \mathrm{yr}$ vs $59 \mathrm{yr}, P<0.05$ ).

Data on 62 operated patients were analysed for this study. Of the original 83 patients, 9 had died, 4 were too ill to be questioned and died shortly after the planned second assessment, 2 patients could not be retraced, and data from 4 patients were incomplete (scores on two or more QL indicators were missing at one assessment point) and hence excluded from further analysis. The operation technique for one patient diverged strongly from that of the others which led to exclusion from the analysis. One other patient did not return his questionnaire.

Table I. Mean age, SD and male: female distribution of patients under study

\begin{tabular}{lrrrr}
\hline & & \multicolumn{2}{c}{ Age } & \\
\cline { 3 - 4 } & $n$ & Mean & SD & $\begin{array}{c}\text { Male:female } \\
\text { ratio }\end{array}$ \\
\hline Interviewed & 132 & 60.6 & 10.4 & $94: 38$ \\
Inoperable & 49 & 63.2 & 10.2 & $38: 11$ \\
Operated & 83 & 59.1 & 10.3 & $56: 27$ \\
Analysed & 62 & 58.1 & 9.9 & $42: 20$ \\
\hline
\end{tabular}


In 52 patients the stomach (or its lower part) was used to restore the digestive tract. In another 5 patients reconstruction was performed by colon interposition, whereas other combinations of resection and reconstruction were used in the remaining 5 . Surgical treatment was preceded by radiotherapy (combined treatment) in 27 out of 62 patients. Mean time interval between operation and postoperative assessment was 4 months (range: $44-285$ days). This range was rather wide, due to slow recovery and complications in some patients and delay in returning questionnaires (e.g. holidays, a long stay with relatives). At the first assessment, $81 \%$ of the patients were married, $48 \%$ were still employed (including part-time employment and housekeeping); $60 \%$ had 10 years of education or less.

\section{Methods}

An adapted version of the Rotterdam Symptom Checklist (RSCL) [5, 19-23] was used to measure psychological distress, physical symptoms and activity level. The reliability of the original scales of the RSCL is good and validity of this instrument is promising [23]. The adapted version used in this study included only five psychological items (11 in the original 30 -item version); 8 physical items were omitted, and eleven specific symptoms related to oesophageal cancer were added. Shortening the psychological scale did not result in a lower reliability index (the 7-item and 5-item versions were equally reliable, i.e. 0.88 , in a study of radiotherapy patients*). Omission of the physical items with low prevalence in this radiotherapy study did not result in dramatic changes in the index for internal consistency (an increase from 0.78 for the original version to 0.80 for a shortened version with 12 items). Both the scores on the shortened physical scale, and the shortened psychological scale correlated strongly with the original scale scores ( $r=0.96$ and 0.98 , respectively). Therefore, shortening by means of omission of items is a legitimate procedure.

Two items of the original Activity Level-scale ('shopping' and 'going to work') were omitted and two other items wcre combined to form one new item. Three other items that are very specific for this patient population (lifting things, bending, and horizontal position in bed), were added. These movements are often difficult for these patients, as is maintaining a normal position in bed, because of the possible reflux of gastric acid.

-Each item was scored on a four-point rating scale, with alternatives 'no burden at all' (score $=1$ ) to 'very burdensome' (score $=4$ ). The scores for 19

*The consequences of shortening were studied on data of 156 radiation-therapy patients with lung cancer, prostatic cancer, gynaecological cancers, or cancer of the bladder. Factor analysis resulted in a 7-item psychological distress scale. Four out of 11 items had low loadings on the psychological factor. physical items were added to form a physical complaint index (Physical Symptoms); a psychological distress index (Psychological Distress) was formed by adding the scores on the 5 psychological items; 3 items related to swallowing problems resulted in a swallowing score (Swallowing Problems). The scores on the Physical Symptoms scale could range from 19 to 76, those on the Psychological Distress Scale from 5 to 20 , and those on the Swallowing Problem Scale from 3 to 12 .

-The 8 items of the scale for Activity Level [21] were each followed by three precoded alternatives: 'unable to do this activity', 'can do it with some effort', or 'can do it as before' (normal). The Activity Level score could range from 8 (normal activities) to 24 (strongly impaired). The items comprised walking about the house, climbing stairs, bending, lifting things, maintaining a normal position in bed, caring for oneself, walking outdoors, housekeeping, and doing odd jobs.

Additionally, problems with food intake were assessed (Food Intake). Patients were categorized as follows: eating without difficulty (normal, score $=1$ ); with some difficulty (score $=2$ ); eating only soft or mashed food (without difficulty, score $=3$; with difficulty, score $=4$ ); only liquid food (score $=5$ ).

Finally, four Global Evaluations were made, concerning:

(a) the total situation in the previous 3 months,

(b) the total situation in the previous 3 days,

(c) the prevailing mood during the previous 3 days, and

(d) physical well-being during the previous 3 days.

Patients responded on a five-point rating scale, ranging from 1 (very good) to 5 (very poor). Scores on these items were added.

High scores on all scales corresponded with a low QL. Scores on the various scales were defined as missing if the scores on a number of items were missing: $\geqslant 8$ physical items, $\geqslant 3$ psychological items, 3 food intake items, $\geqslant 2$ items of the following: Swallowing Problems, Global Evaluations, and Activity Level. If the number of missing item scores was lower than that defined by these criteria, the missing item score was substituted by ' 1 ' for the physical symptoms (including swallowing), the psychological items, and the activity items, or ' 3 ' in the case of Global Evaluations. These procedures resulted in missing values for Global Evaluations (one preoperatively and one postoperatively), for postoperative Activity Level (1X), and for Food Intake (9X).

\section{Reliability}

All scales turned out to have a good reliability. Internal consistencies (Cronbach's $\alpha$ [24]) were generally high: $0.84,0.83,0.74,0.90$, and 0.95 for baseline data $(n=132)$ for Global Evaluations, Physical Symptoms, Swallowing Problems, Psychological Distress, and Activity Level, respectively. 
Table 2. Intercorrelations (Spearman correlations) between QL indicators before and after surgical treatment, calculated for patients participating in both assessments $(n=62)$. (Above diagonal: preoperative data, below diagonal: postoperative data)

\begin{tabular}{|c|c|c|c|c|c|}
\hline & $\begin{array}{c}\text { Physical } \\
\text { symptoms } \\
1\end{array}$ & $\begin{array}{c}\text { Psychological } \\
\text { distress } \\
2\end{array}$ & $\begin{array}{c}\text { Global } \\
\text { evaluations } \\
3\end{array}$ & $\begin{array}{c}\text { Activity } \\
\text { level } \\
4\end{array}$ & $\begin{array}{c}\text { Swallowing } \\
\text { problems } \\
5\end{array}$ \\
\hline \multicolumn{6}{|c|}{ Before surgery } \\
\hline 1 & - & $0.43^{3}$ & $0.44^{3}$ & 0.22 & $0.38^{3}$ \\
\hline 2 & $0.48^{3}$ & - & $0.60^{3}$ & $0.32^{2}$ & $0.26^{\prime}$ \\
\hline 3 & $0.44^{3}$ & $0.68^{3}$ & - & $0.25^{1}$ & $0.36^{2}$ \\
\hline 4 & $0.57^{3}$ & $0.42^{3}$ & $0.43^{3}$ & - & 0.10 \\
\hline 5 & $0.36^{3}$ & $0.26^{1}$ & 0.16 & $0.30^{2}$ & - \\
\hline \multicolumn{6}{|c|}{ After surgery } \\
\hline
\end{tabular}

${ }^{1} P<0.05 ;{ }^{2} P<0.01 ;{ }^{3} P<0.001$.

\section{Statistics}

Statistical methods used are mentioned in the text. All $P$-values are two-sided, and $\alpha=0.05$. When scores for individual complaints were compared, two statistical strategies were followed. In the first (McNemar nonparametric test [25]), the change in the number of patients reporting a symptom at the preoperative measurement, compared with the postoperative measurement, was tested. In the second strategy (Wilcoxon nonparametric test [25]) changes in prevalence and in severity (e.g. from 'a little bit' to 'very much') of existing symptoms were accounted for.

\section{RESULTS}

\section{Age, gender and $Q L$}

There were no significant correlations (Spearman rank-correlations [25]), either at the first or the second assessment, between age and the QL indicators (Global Evaluations, Psychological Distress, Physical Symptom, Activity Level, Swallowing Problems and Food Intake). Mean preoperative Activity Level for either sex did not differ significantly, but did differ postoperatively (Mann-Whitney test, $P<0.05$ ): women were more impaired than men. No other differences on the QL indices were found between men and women.

\section{Type of treatment and $Q L$}

Methods of surgery (type of resection, type of reconstruction, combination of both types) were not significantly related to any of the QL-indices (nonparametric tests, Mann-Whitney and Wilcoxon, $P>0.05$ ). Analyses of variance were carried out for the postoperative $Q L$ scores, with preoperative values as covariates (ANOVA [25]). Although the covariates explained a significant proportion of the variance in the postoperative scores, no significant main effects of medical factors were found

For 27 patients preoperative radiation therapy, resulted in lower mean scores on the Swallowing Problems (referring to fewer problems with the passage of food following therapy; Wilcoxon test), but it did not affect the other QL scores.
As mentioned above, there was a wide range in the time intervals between the two assessments and also between the operation and follow-up. There were, however, no significant associations between length of time intervals and QL scores at the second assessment (Spearman correlations). Likewise, time intervals were unrelated to changes in $\mathrm{QL}$ between the first and the second assessment (partial Pearson correlations)

\section{Relations between $Q L$ indicators}

The Physical Symptoms, Psychological Distress, Global Evaluations and Swallowing Problems showed significant intercorrelations at both measurements (Table 2)

The postoperative correlations between Activity Level and Physical Symptoms, Psychological Distress and Global Evalutions where higher than those at the preoperative assessment. This is probably caused by the greater variation in postoperative Activity Level: the Activity Level for many patients decreased as a consequence of the operation.

There was some stability in QL scores: patients who scored high or low on the Physical Symptoms, Psychological Distress, and Global Evaluations before treatment, tended to score similarly high or low after treatment (Spearman correlations were $0.37,0.54$ and 0.36 , ior the Physical Symptoms, Psychological Distress and Global Evaluations, respectively). This stability was particularly strong in Psychological Distress and almost absent in the scores on the Activity Level and Swallowing Problems $(0.17$ and 0.08 , respectively).

Food Intake correlated significantly with the postoperative Physical Symptoms (0.23), Global Evaluations (0.25), Activity Level (0.32), and Swallowing Problems (0.33). The correlation between Food Intake and Psychological Distress was not significant at the 0.05 level.

\section{Symptoms}

Table 3 lists the 3 items concerning swallowing, the 19 physical symptoms and the 5 psychological symptoms, with percentages of patients who mentioned each symptom before or after the operation.

Preoperative percentages were highest for psychological symptoms (Section $\mathrm{C}$ ). Of the swallowing symptoms, 'difficulty with swallowing' and 'pain when swallowing', were, as expected, mentioned frequently. Tiredness was also often reported $(58 \%)$

The decrease in the percentages of patients with 'pain when swallowing' was significant. Most other physical complaints were reported after the operation more often than before (McNemar's nonparametric test). Changes were statistically significant in 8 items When changes in scores were taken into account (Wilcoxon's test for related samples), the changes in 
Table 3. Percentages of patients reporting problems with swallowing (Section A), physical symptoms (Section B) and psychological symptoms (Section $C)$ before and following surgery $(n=62)$. Columns 2 and 3: percentages; column 4: $P$ values (derived from McNemar's test for correlated proportions)

\begin{tabular}{|c|c|c|c|}
\hline & Preoperative & Postoperative & $P$ \\
\hline $\begin{array}{l}\text { Section A: swallowing } \\
\text { Pain when swallowing } \\
\text { Choking } \\
\text { Difficulty with swallowing }\end{array}$ & $\begin{array}{l}47 \\
19 \\
47\end{array}$ & $\begin{array}{l}24 \\
23 \\
31\end{array}$ & $\begin{array}{l}0.01 \\
0.82 \\
0.10\end{array}$ \\
\hline $\begin{array}{l}\text { ection B: physical sympton } \\
\text { Loss of taste } \\
\text { Sticky saliva } \\
\text { Bad taste in the mouth } \\
\text { Loss of appetite } \\
\text { Tiredness } \\
\text { Sore muscles } \\
\text { Nausea } \\
\text { Heartburn } \\
\text { Belching } \\
\text { Shortness of breath } \\
\text { Dry mouth } \\
\text { Bringing up mucous } \\
\text { Vomiting } \\
\text { Back pain } \\
\text { Pain at breastbone } \\
\text { Stomach ache } \\
\text { Coughing } \\
\text { Hoarse voice } \\
\text { Diarrhoea }\end{array}$ & $\begin{array}{r}16 \\
26 \\
39 \\
26 \\
58 \\
29 \\
21 \\
18 \\
50 \\
26 \\
39 \\
39 \\
13 \\
36 \\
48 \\
19 \\
47 \\
18 \\
6\end{array}$ & $\begin{array}{l}27 \\
27 \\
31 \\
52 \\
82 \\
58 \\
37 \\
21 \\
52 \\
60 \\
47 \\
58 \\
26 \\
60 \\
45 \\
29 \\
60 \\
31 \\
39\end{array}$ & $\begin{array}{c}0.17 \\
1.00 \\
0.42 \\
<0.001 \\
<0.001 \\
<0.001 \\
0.05 \\
0.82 \\
1.00 \\
<0.001 \\
0.41 \\
0.02 \\
0.08 \\
0.02 \\
0.86 \\
0.26 \\
0.12 \\
0.13 \\
<0.001\end{array}$ \\
\hline $\begin{array}{l}\text { ection C: psychological sy } \\
\text { Worried } \\
\text { Depressed } \\
\text { Desperate about future } \\
\text { Stressed } \\
\text { Anxious }\end{array}$ & $\begin{array}{l}\text { oms } \\
77 \\
61 \\
55 \\
77 \\
68\end{array}$ & $\begin{array}{l}55 \\
48 \\
24 \\
58 \\
37\end{array}$ & $\begin{array}{c}<0.001 \\
0.15 \\
<0.001 \\
0.02 \\
<0.001\end{array}$ \\
\hline
\end{tabular}

'depression' and in 'difficulty with swallowing' (referring to a better QL postoperatively), and in 'vomiting', 'coughing' and 'hoarse voice' (referring to a deteriorated $\mathrm{QL}$ ) were also significant.

\section{$Q L$ indicators}

Mean scores on Physical Symptoms and Activity Level increased between the preoperative and the postoperative assessments, indicating a deterioration of QL (Table 4). Mean scores on Psychological Distress and Swallowing Problems decreased (improvement) between the preoperative and postoperative assessments. The mean change in Global Evaluations was not significant.

Changes in mean scores can present a distorted picture and sometimes mask dramatic individual changes in clinically significant proportions of
Table 4. Mean scores (SD) on scales for Physical Symptoms, Psychological Distress, Global Evaluation, Activity Level, and Swallowing Problems, before treatment and after treatment $(n=62)$. The last column contains $\boldsymbol{P}$ values from Wilcoxon's test (paired observations)

\begin{tabular}{lccc}
\hline & Before & After & \\
& surgery & surgery & $P$ \\
\hline Physical Symptoms & $26.8(6.5)$ & $31.7(7.9)$ & $<0.001$ \\
Psychological Distress & $10.0(3.4)$ & $7.8(3.0)$ & $<0.001$ \\
Global Evaluations & $8.9(2.7)$ & $8.7(2.7)$ & 0.48 \\
Activity Level & $9.4(3.0)$ & $11.1(3.1)$ & $<0.001$ \\
Swallowing Problems & $4.8(2.1)$ & $4.1(1.6)$ & 0.04 \\
\hline
\end{tabular}

patients with a deteriorated postoperative QL (see Table 5). For instance, there was an improvement in the mean score on Swallowing Problems, but $18 \%$ of the patients reported a worsening in this respect. Mean Global Evaluations score was unchanged, but postoperative evaluations were more negative than preoperative evaluations in $25 \%$ of the cases.

\section{DISCUSSION}

Quality of Life is becoming an increasingly important concept in the treatment of cancer patients, especially when the prognosis is unfavourable. There are several procedures to assess QL. Some researchers have restricted themselves to purely medical indicators (e.g. complications, side-effects), while others have used physical indicators, assuming that these must have important consequences for psychosocial functioning (e.g. activity level, swallowing ability, hair loss). A third group emphasizes the importance of psychological sequelae (distress, depression, anxiety).

The decision about what indicator to choose depends partly on the topic of interest in the decision maker. When an oncologist is interested in the effect of treatment per se, his or her attention will be directed to specific, physical indicators, often differing between treatments and cancer sites. When care is extended beyond the physical level, then the oncologist, psychiatrist or psychologist will probably also use psychological indicators to assess QL.

The psychological scales used in this study cover several aspects of the Quality of Life of cancer patients, ask for subjective evaluations by the patients, and are reliable instruments. If well-being or Global Evaluations are taken as criteria for QL,

Table 5. Percentages of patients in 5 groups of decreased, increased or unchanged Quality of Life scores

\begin{tabular}{lccccc}
\hline & $\begin{array}{c}\text { Physical } \\
\text { symptoms }\end{array}$ & $\begin{array}{c}\text { Psychological } \\
\text { distress }\end{array}$ & $\begin{array}{c}\text { Global } \\
\text { evaluations }\end{array}$ & $\begin{array}{c}\text { Activity } \\
\text { level }\end{array}$ & $\begin{array}{c}\text { Swallowing } \\
\text { problems }\end{array}$ \\
\hline Extreme deterioration & 20 & 3 & 13 & 24 & 2 \\
Moderatc detcrioration & 29 & 8 & 12 & 30 & 16 \\
Unchanged & 40 & 32 & 42 & 36 & 56 \\
Moderate improvement & 8 & 18 & 22 & 2 & 15 \\
Extreme improvement & 3 & 39 & 11 & 8 & 11 \\
\hline
\end{tabular}

Extreme deterioration or improvement: Physical Symptoms Score: a difference of 10 or more units; Psychological Distress, Global Evaluation, Activity Level, Swallowing Problems: a difference of 4 or more units.

Moderate deterioration or improvement: Physical Symptoms Score: 5-9 units difference; Psychological Distress, Global Evaluation, Activity Level, Swallowing Problems: a difference of 2 or 3 units.

Unchanged: Physical Symptom Score: 0-4 units difference; Psychological Distress, Global Evaluation, Activity Level, Swallowing Problems: a difference of 0 or 1 unit. 
then swallowing problems can only partly account for the variations in these evaluations. Psychological distress turns out to be a strong correlate of Global Evaluation. Problematic postoperative food intake correlated significantly with other $\mathrm{QL}$ indicators (Activity Level, Global Evaluations), but the associations were not very strong.

The present study on the QL of surgically treated patients with oesophageal cancer, leads to different conclusions, depending on the specific indicator chosen. It can be concluded, from a strictly medical point of view, that the main problems patients were suffering from, have adequately been treated in most cases, leading to less pain and fewer problems during swallowing. When other physical symptoms and the effect on activity level are taken into account, the conclusions are quite the opposite: patients were left with a seriously deteriorated QL. In a psychological sense, however, QL improved: patients experienced less distress after surgery. The global evaluation probably combines these different approaches: there was hardly any change in the mean score on this index.

The opposing developments in physical burden and psychological distress refer to the notion that these patients probably accept a great deal of physical discomfort in exchange for gaining an outlook on a longer life. In our cases there was such a perspective on a longer life (maybe with some impairment).

Many patients will experience an increase in swallowing ability and this will be seen as a first step towards complete recovery. They expect further physical improvement in the near future, since only 3-5 months have passed since surgery and so far, their physical functioning was improved each day. In these cases there is hope for cure and a complete recovery.

Three, four or five months, however, is a short period of time to evaluate the results of treatment in terms of QL. It can be argued that a longer period is needed to adequately evaluate postoperative QL. This is, however, not supported by the low correlations between length of time interval and postoperative QL-indices.

It could be argued that the QL-changes are different for patients who died a few months after the second assessment, as compared with patients who survive longer. Quality of Life may be correlated with the remaining time to live. This possibility has not been tested here.

Finally, it must be stressed that the global mcasures of medical factors (type of treatment) did not lead to significant differences (or changes) in QL. This is in line with other studies $[26,27]$. Our results demonstrate that swallowing problems and food intake play a minor role in the patient-evaluation of QL. We found some significant correlations between swallowing problems and other indicators, but these problems only had a small impact on psychological distress and Global Evaluations. Psychological processes (e.g. coping strategies
[28, 29], and social support [30]) may be responsible for a positive QL despite a deterioration in the physical condition.

QL-data concerning specific symptoms can be complementary to the clinical evaluations of treatments. Patients can be informed about specific and general somatic symptoms prior to treatment. Psychological data and global evaluations can form guidelines for evaluation psychological support. More research on psychological factors (denial, coping, hope, anxiety) as determinants of $\mathrm{QL}$ is needed in order to improve psychological support, resulting in a better QL after treatment.

Acknowledgements - This study was granted by the Dutch Cancer Society. The authors are most grateful to Dr B. Bonke of the Department of Medical Psychology and Psychotherapy of the Erasmus University for critically reviewing the manuscript.

\section{REFERENCES}

1. Haes J. C. J. M. de and Knippenberg F. C. E. van. The Quality of Life of Cancer Patients. Soc. Sci. Med. 20, 809-817, 1985 .

2. Aaronson N. K. and Beckmann J. (Eds) The Quality of Life of Cancer Patients. EORTC MONOGRAPH, Raven Press, New York, 1987.

3. Bardelli D. and Saracci R. Measuring the quality of life in cancer clinical trials: a sample survey of published trials. In Methods and Impact of Controlled Therapeutic Trials in Cancer. UICC Technical Report Series, Vol. 36, pp. 75-97, 1978.

4. Calman K. C. Definitions and dimensions of quality of life. In The Quality of Life of Cancer Patients (Edited by Aaronson N. K. and Beckmann J.). EORTC MONOGRAPH, Raven Press, New York, 1987.

5. Knippenberg F. C. E. van and Haes J. C. J. M. de. Measuring quality of life in cancer patients: psychometric qualities of instruments. J. clin. Epidem. 41, 1043-1051, 1988.

6. Eeftinck Schattenkerk M., Obertop H., Mud H. J., Eijkenboom W. M. H., Andel J. G. and van Houten H. Survival after resection for carcinoma of the oesophagus. Br. J. Surg. 74, 165-168, 1987.

7. Earlam R. and Cunha-Melo J. R. Oesophageal squamous cell carcinoma: 1 . A critical review of surgery. Br. J. Surg. 67, 381-390, 1980.

8. Müller J. M., Erasmi H., Stelzner M., Zieren U. and Pichilmaier H. Surgical treatment of oesophageal carcinoma. Br. J. Surg. 77, 845-857, 1990.

9. Tilanus H. W. and Langenhorst B. L. A. M. Oesophagusresectie en reconstructie zonder thoracotomie; eerste ervaringen. Ned. Tijdschr. Geneeskd. 134, 2237-2240, 1990.

10. Dijkhuis C. M. De behandeling van slokdarmkanker. Dissertation. Erasmus University Rotterdam, 1982.

11. Fornaro P., Sauberli H., Baumgartner D., Largiader F. and Deyhle P. Der Häring-Tubus in der Palliativ Chirurgic der Inoperablen Osophaguskarzinoms: eine Verbesserung der Lebensqualität? Helv. Chir. Acta 43, 533-536, 1976

12. Diamantes $\mathbf{T}$. and Mannell A. Oesophageal intubation for advanced oesophageal cancer: The Baragwanath experience. Br. J. Surg. 70, 555-557, 1983.

13. Barbier P., Kappeler M., Teuscher J. and Scheurer U. Erfahrungen mit Endoskopisch Plazierten Endoprothesen bei Stenosierenden Malignomen von Oesophagus und Kardia. Chirurg 55, 593-599, 1984. 
14. Ellis F. H., Gibb S. P. and Watkins E. A safe widely applicable and expeditious form of palliation for patients with carcinoma of the oesophagus and cardia. Ann. Surg. 198, 531-540, 1983.

15. Watson A. A study of the quality and duration of survival following resection, endoscopic intubation and surgical intubations in oesophageal carcinoma. $B r . J$. Surg. 69, 585-588, 1982.

16. Pralat H., Dragojevic D., Hetzer R. and Borst H. G. Langzeit-Ergebnisse nach Resektion und Speisewegrekonstruktion beim Oesophagus Carcinom. Langenbechs Arch. Chir. 360, 251-265, 1983.

17. Sugimachi K., Maekawa S., Koga Y., Ueo H. and Inokuchi $\mathbf{K}$. The quality of life is sustained after operation for carcinoma of the esophagus. Surg. Gynaec. Obst. 62, 544-546, 1986.

18. Stoller J. L., Samer K. J., Toppin D. I. and Flores A. D. Carcinoma of the Oesophagus: A new proposal for the evaluation of treatment. Can. J. Surg. 454459 , 1987.

19. Haes J. C. J. M. de, Knippenberg F. C. E. van and Neyt J. Measuring physical and psychological distress in cancer patients: structure and application of the Rotterdam Symptom Checklist. Br. J. Cancer 62, 1034-1038, 1990.

20. Cella D. F. and Tulsky D. S. Measuring quality of life today: methodological aspects. Oncology 4, (5), 29-38, 1990.
21. Haes J. C. J. M. de, Pruyn J. F. A. and Knippenberg F. C. E. Een Klachtenlijst voor kankerpatienten: eerste ervaringen. Ned. Tdschr. Psychol. 38, 403-422, 1983.

22. Hopwood P., Howell A. and Maguire P. Screening for psychiatric morbidity in patients with advanced breast cancer: validation of two self-report Questionnaires. $\mathrm{Br}$. J. Cancer 64, 353-356, 1991.

23. Maguire P. and Selby P. Assessing quality of life in cancer patients. Br. J. Cancer 60, 437-442, 1989.

24. Cronbach L. J. Coefficient alpha and the internal structure of tests. Psychometrika 16, 297-334, 1951.

25. Nie H. N. Statistical Package for the Social Sciences SPSSX, User Guide. McGraw Hill, New York, 1983.

26. Najman J. M. and Levine S. Evaluating the impact of medical care and technologies on the quality of life: a review and critique. Soc. Sci. Med. 15, 107-115, 1981.

27. Sugarbaker P. H., Barofsky I., Rosenberg St A. and Gianola F. J. Quality of life assessments of patients in extremity sarcoma clinical trials. Surgery 91, (1), 17-23, 1982.

28. Manuel G. M., Roth S., Keefe F. J. and Brantley B. A Coping with Cancer. J. Hum. Stress 149-158, 1987.

29. Meyerowitz B. E. Psychological correlates of breast cancer and its treatments. Psych. Bull. 87, (1), 108-131, 1980

30. Wortman C. B. Social support and the cancer patient; conceptual and methodological issues. Cancer Suppl. 53, (10), 2339-2362, 1984 